\section{Identification of non-sporing anaerobic bacteria}

\author{
D. A. LEIGH AND K. SIMMONS Pathology Laboratory, \\ Wycombe General Hospital, High Wycombe, Bucks, \\ UK
}

Over the last few years there has been a notable increase in the incidence of isolation of anaerobic bacteria in routine hospital laboratories. Careful collection of clinical specimens usually transported to the laboratory in special media, maintaining an anaerobic environment, and selective culture media have all played a significant role. The identification of anaerobic bacteria, particularly non-sporing Gramnegative bacilli, however, is difficult in the routine hospital laboratory where it is important to issue a report as quickly as possible so that the patient can receive appropriate chemotherapy. The major characteristics of this group of bacteria, which include acid end products of fermentation, threonine degradation, and end $\mathrm{pH}$ in glucose broth, require expensive equipment and prolonged incubation. Finegold et al. (1967) first reported that antibiotic susceptibility patterns were a useful aid to identification and they suggested the use of six antibioticserythromycin, rifampicin, colistin, penicillin, kanamycin, and vancomycin. High concentration discs were used to differentiate between the main groups of Gram-negative anaerobic bacteria (Sutter and Finegold, 1971; Sutter et al., 1972). Other methods such as the API 20A anaerobic technique (API Laboratory Products Ltd, Rayleigh, Essex) are available but have the disadvantages of expense and of prolonging the time before the clinical report can be issued.

At Wycombe the range of six antibiotics has been used in the form of single discs as a rapid identification method with considerable interest and success. The range of antibiotics is now available on a single Mastring MID 8 available from Mast Laboratories Ltd, Liverpool, and this paper reports an experience using this new method.

\section{Methods}

One hundred and sixty-three strains of anaerobic bacteria were studied using the new Mastring. One hundred and fifty-three strains had been isolated from clinical infections and this number includes 10 strains of Fusobacterium supplied by Professor Brumfitt, The Royal Free Hospital, London and 12 strains (8 Fusobacterium and 4 Bacteroides oralis) supplied by

Received for publication 12 April 1977
Dr H. R Ingham, The General Hospital, Newcastle upon Tyne. Ten reference strains obtained from the National Collection of Type Cultures, Colindale, London were also tested.

The strains were inoculated onto blood agar plates made of tryptone soy agar containing $5 \%$ defibrinated horse blood both by direct culture from several colonies using a loop and by making a bacterial suspension in thioglycollate broth and flooding the agar plate. In each case the resulting bacterial growth was just confluent. The Mastring was applied and anaerobic incubation was carried out using the Gaspak technique.

The six antibiotics on the Mastring and the concentrations used were as follows: erythromycin $(60$ $\mu \mathrm{g})$, rifampicin $(15 \mu \mathrm{g})$, colistin $(10 \mu \mathrm{g})$, penicillin $(2$ units), kanamycin $(1000 \mu \mathrm{g})$, and vancomycin $(5 \mu \mathrm{g})$. The plates were examined and the zones measured at 24 and 48 hours. The identity of the strains was confirmed by cell morphology and in most cases by the API 20A technique.

\section{Results}

The susceptibility patterns of the strains of anaerobic bacteria are shown in the Table and, in general, identification was clear cut, although there were a few exceptions.

The 115 strains identified as Bacteroides fragilis were uniformly resistant to penicillin, kanamycin, and vancomycin, and, with one exception, to colistin. All strains were sensitive to rifampicin and 112 strains were sensitive to erythromycin. The finding that three strains of $B$. fragilis were resistant to erythromycin was not unexpected as a small minority of strains have minimal inhibitory concentrations exceeding $25 \mu \mathrm{g}$ per $\mathrm{ml}$.

Although it was difficult to differentiate between the patterns of susceptibility found with $B$. melaninogenicus and oralis the five strains of oralis were all sensitive to colistin and resistant to kanamycin whereas with the 11 strains of melaninogenicus there was considerable variation in susceptibility to colistin and three strains were sensitive to kanamycin. Strains of $B$. corrodens are readily identified by colonial morphology but the antibiotic pattern was the same as for Veillonella species, being uniformly sensitive to all antibiotics except for vancomycin. The Fusobacterium group presented the greatest variation, and the difficulties associated with this group are well known. There are many sub species and the classification is not fully agreed. Sixteen of the 18 strains were resistant to erythromycin and 10 to rifampicin. There was uniform sensitivity to colistin, penicillin, and kanamycin. Although the cocci can be differentiated easily on cellular mor- 
Table Antibiotic susceptibility patterns of non-sporing anaerobic bacteria

\begin{tabular}{|c|c|c|c|c|c|c|}
\hline Bacteria & $\begin{array}{l}\text { Erythromycin } \\
60 \mu \mathrm{g}\end{array}$ & $\begin{array}{l}\text { Rifampicin } \\
15 \mu \mathrm{g}\end{array}$ & $\begin{array}{l}\text { Colistin } \\
10 \mu \mathrm{g}\end{array}$ & $\begin{array}{l}\text { Penicillin } \\
2 \text { units }\end{array}$ & $\begin{array}{l}\text { Kanamycin } \\
1000 \mu \mathrm{g}\end{array}$ & $\begin{array}{l}\text { Vancomycin } \\
5 \mu g\end{array}$ \\
\hline $\begin{array}{l}\text { Bacteroides fragilis } \\
\text { (115 strains) }\end{array}$ & $\mathbf{S}^{\mathbf{r}}$ & $\mathbf{S}$ & $\mathbf{R}^{\mathbf{s}}$ & $\mathbf{R}$ & $\mathbf{R}$ & $\mathbf{R}$ \\
\hline $\begin{array}{l}\text { Bacteroides melaninogenicus } \\
\text { (11 strains) }\end{array}$ & $\mathbf{S}$ & $\mathbf{S}$ & $\mathbf{V}$ & $\mathbf{S}$ & $\mathbf{R}^{\mathbf{s}}$ & $\mathbf{R}$ \\
\hline $\begin{array}{l}\text { Bacteroides oralis } \\
\text { (5 strains) }\end{array}$ & $\mathbf{S}$ & $\mathbf{S}$ & $\mathbf{S}$ & $\mathbf{S}$ & $\mathbf{R}$ & $\mathbf{R}$ \\
\hline $\begin{array}{l}\text { Bacteroides corrodens } \\
\text { (3 strains) }\end{array}$ & $\mathbf{S}$ & $\mathbf{S}$ & $\mathbf{S}$ & $\mathbf{S}$ & $\mathbf{S}$ & $\mathbf{R}$ \\
\hline $\begin{array}{l}\text { Fusobacterium species } \\
\text { (18 strains) }\end{array}$ & $\mathbf{R}^{\mathbf{s}}$ & $\mathbf{R}^{\mathbf{s}}$ & $\mathbf{S}$ & $\mathbf{S}$ & $\mathbf{S}$ & $\mathbf{R}$ \\
\hline $\begin{array}{l}\text { Gram-positive cocci } \\
\text { (10 strains) }\end{array}$ & $\mathbf{S}$ & $\mathbf{S}$ & $\mathbf{R}$ & $\mathbf{S}$ & $\mathbf{S}$ & $\mathbf{S}$ \\
\hline $\begin{array}{l}\text { Gram-negative cocci } \\
\text { (1 strain) }\end{array}$ & $\mathbf{S}$ & $\mathbf{S}$ & $\mathbf{S}$ & $\mathbf{S}$ & $\mathbf{S}$ & $\mathbf{R}$ \\
\hline
\end{tabular}

$\mathbf{S}=$ sensitive $; \mathbf{S}^{\mathbf{r}}=$ occasional strains resistant $; \mathbf{V}=$ variable $; \mathbf{R}=$ resistant $; \mathbf{R}^{\mathbf{s}}=$ occasional strains sensitive.

phology, the susceptibility patterns of Gram-positive strains are distinct. The zone diameters for all antibiotics were large with sensitive strains, the majority exceeding $10 \mathrm{~mm}$ (excluding disc diameter) and many $25 \mathrm{~mm}$.

The arrangement of the antibiotics on the Mastring was primarily designed to allow easy identification of $B$. fragilis, the species most commonly isolated in the routine hospital laboratory, and no technical difficulties in regard to either inhibition or synergy were found with the strains tested.

\section{Discussion}

This new Mastring provides an easy and reliable method of primary identification of non-sporing anaerobic bacteria. The result is available at the same time as the therapeutic antibiotic sensitivities, usually after 24 hours' incubation, and does not delay the issue of the laboratory report. The Mastring, in common with all other antibiotic-impregnated discs, must be kept in sealed containers in the refrigerator at between 4 and $10^{\circ} \mathrm{C}$ and can be expected to have a storage life of 12 months. Under these conditions reproducible results will be obtained. The size or age of the inoculum was not found to affect the result although it is preferable to use a young culture and heavy inoculum in order to obtain readable zones after overnight incubation with the more rapidly growing species such as Bacteroides.

No significant difference was found between the methods of inoculating the blood agar plates although the flooding technique produced a more standard result and the zones were more easily read.

In this study the Gaspak method of producing anaerobiosis was used and was found to be satisfactory. Although there are certain predictable difficulties with this method and the high concentra- tion of $\mathrm{CO}_{2}$ may explain the presence of a few erythromycin resistant strains of $B$. fragilis, most routine hospital laboratories find the Gaspak method the simplest and safest for anaerobic culture.

The differentiation between $B$. oralis and $B$. melaninogenicus is difficult, and it would be necessary to study a large number of strains to determine if separation of the two species is possible by this method. From this small study it appears that strains resistant to colistin or sensitive to kanamycin are more likely to be $B$. melaninogenicus. Other morphological features such as pigment production may be helpful.

Routine hospital laboratories experiencing difficulties of an increasing workload and lack of staff should find this new Mastring of value in the identification of anaerobic bacteria.

The Mastrings were supplied by Mr K. C. Ashley, Mast Laboratories, Mast House, Derby Road, Bootle, Merseyside, L20 1EA.

\section{References}

Finegold, S. M., Harada, N. E., and Miller, L. G. (1967). Antibiotic susceptibility patterns as aids in classification and characterization of gram-negative anaerobic bacilli. Journal of Bacteriology, 94, 1443-1450.

Sutter, V. L., Attebery, H. R., Rosenblatt, J. E., Bricknell, K. S., and Finegold, S. M. (1972). Anaerobic Bacteriology Manual, p. 23, table 7. Clinical Microbiology Techniques Workshop, September 16-17, 1972.

Sutter, V. L. and Finegold, S. M. (1971). Antibiotic disc susceptibility tests for rapid presumptive identification of Gram negative anaerobic bacilli. Applied Microbiology, 21, 13-20. 